\title{
Comparison of ceramic-on-ceramic bearing vs ceramic-on-highly cross-linked polyethylene-bearing surfaces in total hip arthroplasty for avascular necrosis of femoral head: a prospective cohort study with a mid-term follow-up
}

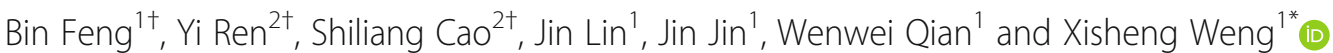

\begin{abstract}
Background: The ideal bearing surface for patients of avascular necrosis (AVN) undergoing total hip arthroplasty (THA) remains controversial. The purpose of this study is to evaluate the clinical outcomes, health-related quality of life (HRQL), and wear of the bearing surface between ceramic-on-ceramic (CoC) and ceramic-on-highly cross-linked polyethylene (COXPE) THA for patients of AVN after midterm follow-up.

Methods: We performed a retrospective case-control analysis of $93 \mathrm{CoC}$ and 77 COXPE consecutive THAs for patients of AVN. The cases were followed at a minimum 5 years follow-up (average 7 years). Harris hip score (HHS) score and bearing-related complications were assessed. The health-related quality of life (HRQL) was assessed with the Short Form 36 (SF-36). Plain radiographs and computed tomography (CT) were used for radiographic evaluation.

Results: Both the CoC group and COXPE group showed statistically significant improvements in HHS scores with no difference between the two bearing surfaces. There was no significant difference as for SF-36 at the latest follow-up between two groups, except for significant higher scores in the dimensions of general health in the CoC group (75.7 vs $64.7, P=0.032$ ). No radiographic evidence of osteolysis and loosening was present at the final followup. The mean wear rate of the CoC was $0.0096 \mathrm{~mm} /$ year and the COXPE was $0.047 \mathrm{~mm} /$ year after evaluation with reconstructed $C T$.
\end{abstract}

Conclusions: COC THAs acts as well as COXPE THAs for patients with femoral head avascular necrosis after midterm follow-up. CoC bearing can significantly decrease the wearing rate than COXPE bearing.

Keywords: Total hip arthroplasty, Avascular necrosis, Bearing surfaces, Wear rate, Health-related quality of life

\footnotetext{
* Correspondence: xshweng@medmail.com.cn

${ }^{\dagger}$ Bin Feng, Yi Ren and Shiliang Cao contributed equally to this work.

${ }^{1}$ Department of Orthopaedic Surgery, Peking Union Medical College Hospital,

Peking Union Medical College, Beijing 100730, China

Full list of author information is available at the end of the article
}

(c) The Author(s). 2019 Open Access This article is distributed under the terms of the Creative Commons Attribution 4.0 International License (http://creativecommons.org/licenses/by/4.0/), which permits unrestricted use, distribution, and reproduction in any medium, provided you give appropriate credit to the original author(s) and the source, provide a link to the Creative Commons license, and indicate if changes were made. The Creative Commons Public Domain Dedication waiver (http://creativecommons.org/publicdomain/zero/1.0/) applies to the data made available in this article, unless otherwise stated. 


\section{Background}

Total hip arthroplasty (THA) has been considered a successful solution for disabling hip conditions after endstage avascular necrosis of the femoral head (AVNF). While the number of overall total joint arthroplasties continues to increase, the greatest rise is projected to be in the young patient population, with $52 \%$ of all joint replacements predicted to be in patients younger than 65 years old [1]. Major limitation affecting THA survivorship in younger patient has been polyethylene (PE) wear and particle-induced osteolysis resulting in aseptic loosening and late failure of the implant [2]. Traditional metal-onpolyethylene (MoP) has the risk of polyethylene wear and mechanically activated corrosion which many increase the risk of revision [3]. Ceramic-on-ceramic (CoC) has the advantage of low levels of wear and is a popular choice of bearing surface for younger patients [4]. Nevertheless, $\mathrm{CoC}$ has its own recognized complication risks (insertional and delayed fracture $[5,6]$ and squeaking $[7,8])$. A ceramic-on-highly cross-linked polyethylene (CoXPE) articulation may decrease long-term wear [9] and potentially have a longer survivorship with less ceramic fracture and squeaking than CoC-bearing surface and is increased use in the younger population (less than 65 years old) over the last 5 years as demonstrated in the National Joint Registry [10]. The previous study has reported the comparative result between $\mathrm{CoC}$ and CoP [11], but the study focused on conventional polyethylene. There is limited data on the comparative result between $\mathrm{CoC}$ and CoXPE. Similarly, health-related quality of life (HRQL) after THA has been reported only in a handful of studies $[12,13]$. In this retrospective study, we aim to evaluate the clinical outcomes, HRQL, complications, and wear rate of the bearing surface between $\mathrm{CoC}$ and CoXPE for THA patients with AVNF with a minimum follow-up of 5 years.

\section{Methods}

\section{Patients and surgical information}

Between January 2009 and December 2012, we performed 140 patients (178 THAs) consecutive primary cementless THAs with CoC or CoXPE for patients with AVNF. The choice of the bearing surface was according to the senior surgeons' preference. Informed consent was obtained from all patients, and the study was approved by the ethics committee of our hospital. The patients were prospectively followed. Of these, 6 patients (7 THAs) were lost to followup and 1 died. The follow-up was concluded in December 2017. In total, 133 patients (170 THAs) were followed with a minimum follow-up of 5 years. The mean follow-up was 7 years (range 5-9 years). Demographic data are presented in Table 1. There is no significant difference between the groups with regard to the distribution of sex and body mass index (BMI). However, there were younger patients in the CoC group (51 years vs 59 years, $P=0.01$ ).
Table 1 Demographics of the avascular necrosis patients undergoing primary total hip arthroplasty with CoC or COXPE bearing with more than 5 years follow-up

\begin{tabular}{llll}
\hline & CoXPE $(n=77)$ & $\operatorname{CoC}(n=93)$ & $P$ value \\
\hline Patients & 62 & 71 & \\
THAs & 77 & 93 & \\
Age (years) & $59(36-79)$ & $51(30-75)$ & $P=0.034$ \\
Sex (male/female) & $44 / 33$ & $53 / 40$ & $P=0.984$ \\
BMl (kg/m2) & $23.2(19.7-28.9)$ & $25.2(19.9-29.3)$ & $P=0.162$ \\
Cause of AVNF & & & \\
$\quad$ Steroids & 57 & 72 & \\
$\quad$ Alcohol & 12 & 15 & \\
$\quad$ traumatic & 8 & 6 & \\
Follow-up (years) & $7.2(5-9)$ & $6.9(5-9)$ & \\
\hline
\end{tabular}

COXPE Ceramic-on-highly cross-linked polyethylene, CoC ceramic on ceramic, $B M I$ body mass index, AVNF avascular necrosis of femoral head. All values were given as the mean and range

All operations were performed through a posterolateral approach in a lateral position. A BIOLOX delta (BIOLOX Delta; CeramTec, Plochingen, Germany) ceramic-on-ceramic bearing was used for the $\mathrm{CoC}$ group. Uncemented femoral component (Corail; DePuy, Warsaw, IN) with an uncemented acetabular component (Pinnacle; DePuy, Warsaw, IN) was used. A BIOLOX delta ceramic on highly cross-linked polyethylene was used for the CoXPE group. The socket was fixed with a target positioning of $20^{\circ}$ of anteversion and $45^{\circ}$ of inclination.

\section{Clinical analysis}

The patients were encouraged to walk on the second postoperative day with the assistance of a crutch. Routine follow-up visits were scheduled for 6 weeks, 3 and 12 months, and then annually thereafter. The clinical outcome was assessed using the Harris hip score (HHS). HRQL was assessed using the Short Form 36 (SF-36). The patients were asked whether any noise had occurred and the type of noise (clicking, squeaking, or other noise). The postoperative complications were recorded, including loosening, ceramic fracture, dislocation, infection, periprosthetic fracture, and reoperation.

\section{Radiographic analysis}

Radiographic outcomes were obtained in the standard anteroposterior (AP) view and in the frog position. The loosening of the component was defined according to Kim's and Sutherland's studies [14, 15]. Osteolysis was defined as areas of endosteal, intracortical, or cancellous bone destruction of $>2 \mathrm{~mm}$ that were non-linear and were progressive [16].

The wear of the liner was measured by using a computed tomography (CT) [17]. Artifact subtract reconstructed CT 
was performed at the latest follow-up. The radiography was measured by two independent surgeons. The annual wear rate was calculated by dividing total femoral head penetration at the end-point of observation by the number of years of follow-up [18] (Fig. 1).

\section{Statistical analysis}

Continuous variables were summarized using means and standard deviation (SD), and categorical variables were summarized using counts and proportions. The level of statistical significance was set at $P<0.05$. A two-way analysis of variance was used to analyze the difference between the $\mathrm{CoC}$ and CoXPE groups for functional outcomes and wear rates. For categorical variables, chisquare analysis was used. All statistical analyses were performed using SPSS 15.0 (SPSS, Inc., Chicago, IL).

\section{Results}

\section{Clinical outcomes}

The mean Harris hip score (HHS) improved from 47.9 points preoperatively to 89.6 points at the final follow-up for $\mathrm{CoC}$ group $(P<0.01)$. The mean HHS improved from 40.4 points preoperatively to 86.7 points at the final follow-up for the CoXPE group $(P<0.01)$. There was no significant difference in the HHS at the final follow-up between the group of $\mathrm{CoC}$ and $\mathrm{CoXPE}(P=0.247)$.

Health-related quality of life (HRQL) was evaluated with Short-Form Health Survey (SF-36) [19] (Table 2). The patients in $\mathrm{CoC}$ group showed significant higher scores in general health than CoXPE group (75.7 vs 64.7, $P=0.032$ ). There was no significant difference between the two groups as for the other dimensions of SF-36. (Table 2).

\section{Radiological outcomes}

All the patients completed the plain radiograph followup. We detected no radiographic evidence of osteolysis and loosening at the final follow-up. One hundred two cases $(60 \%)$ completed the CT follow-up (57 cases for $\mathrm{CoC}, 45$ cases for CoXPE). The minimal resolution of CT measurement was $0.1 \mathrm{~mm}$ in our system. The mean annual liner wear rate was $0.0096 \pm 0.003 \mathrm{~mm} /$ year for the $\mathrm{CoC}$ group according to the reconstruction CT (Fig. 1a), and the mean annual liner wear rate was $0.047 \pm 0.009 \mathrm{~mm} /$ year for the CoXPE group (Fig. 1b). The CoXPE group had a significantly higher annual wear rate than the $\mathrm{CoC}$ group $(P<0.001)$.

\section{Complications}

Three hip dislocations occurred in the CoXPE group (with a ratio of 3.9\%). Two occurred within postoperative 1 year, and one occurred at the 8 years after index operation. Six hip dislocation occurred in the $\mathrm{CoC}$ group (6.5\%). Five occurred within postoperative 1 year, and one occurred at the 6.5 years after index operation. All dislocations were successfully treated conservatively, using a single closed reduction with no recurrence. There was no statistical difference as to the complication of dislocation between the $\mathrm{CoC}$ and CoXPE groups (6.5\% vs $3.9 \%, P=0.459)$ (Table 3 ). One hip had periprosthetic fracture at the distal part of the stem in the CoXPE group after falling and was successfully treated with open reduction and internal fixation. One hip had a superficial infection in the CoXPE group and was successfully treated with debridement. Two hip reported the noise of "snap" when rising from a squatting position in the group of CoXPE. Eight hips reported postoperative noise in the $\mathrm{CoC}$ group, with two for the noise of "grind" and six for the noise of "snap." These noises were not associated with pain or limitation of function. No patients reported squeaking postoperatively in our group. No patients required revision for the noise. There was a higher rate of the compilation of noise for the group of $\mathrm{CoC}$ than the CoXPE $(8.6 \%$ vs $2.6 \%, P=0.098)$ (Table 3). There was no occurrence of ceramic fracture among the $\mathrm{CoC}$ group at the latest follow-up. There were no failures or loss of fixation related to bearing surfaces/wear in both groups.

\section{Discussion}

Although joint registries demonstrate excellent survival using polyethylene [10]. The incidence of osteolysis in conventional polyethylene was almost $18 \%$ [20]. Concerns about wear and osteolysis with polyethylene have led to an increased focus on the use of hard-on-hard articulations. There is a trend for the hard-on-hard bearing surface transition from metal-on-metal to $\mathrm{CoC}$ articulation [10]. Ceramics offer the best wear resistance, wettability, scratch resistance, and scratch profile [21]. $\mathrm{CoC}$ had a lower incidence of osteolysis than metal-on-metal in primary THAs [22]. $\mathrm{CoC}$ bearing was considered to be the ideal bearing surface in the younger, active patient with increased use in younger patients [23]. However, ceramic articulations have the drawbacks of fracture, squeaking, and the risk of acetabular torque [11]. Moreover, head and liner options are limited, such as the lack of a lip liner to improve the stability of the hip. Highly crosslinked-polyethylene also demonstrated good wear resistance $[9,24]$. The new highly crosslinked polyethylene inserts may reduce the risks associated with ceramic implants while retaining their longevity with less wear than conventional poly [25]. According to literature, both $\mathrm{CoC}$ and ceramic-on-plastic bearing showed better implant survival compared with the metal-on-plastic bearing [13].

In this study, there were no failures of bearing surfaces in either the $\mathrm{CoC}$ or CoXPE group in AVN patients who underwent primary THA at an average 7 years follow-up. $\mathrm{CoC}$ THAs demonstrated good wear resistance within a 


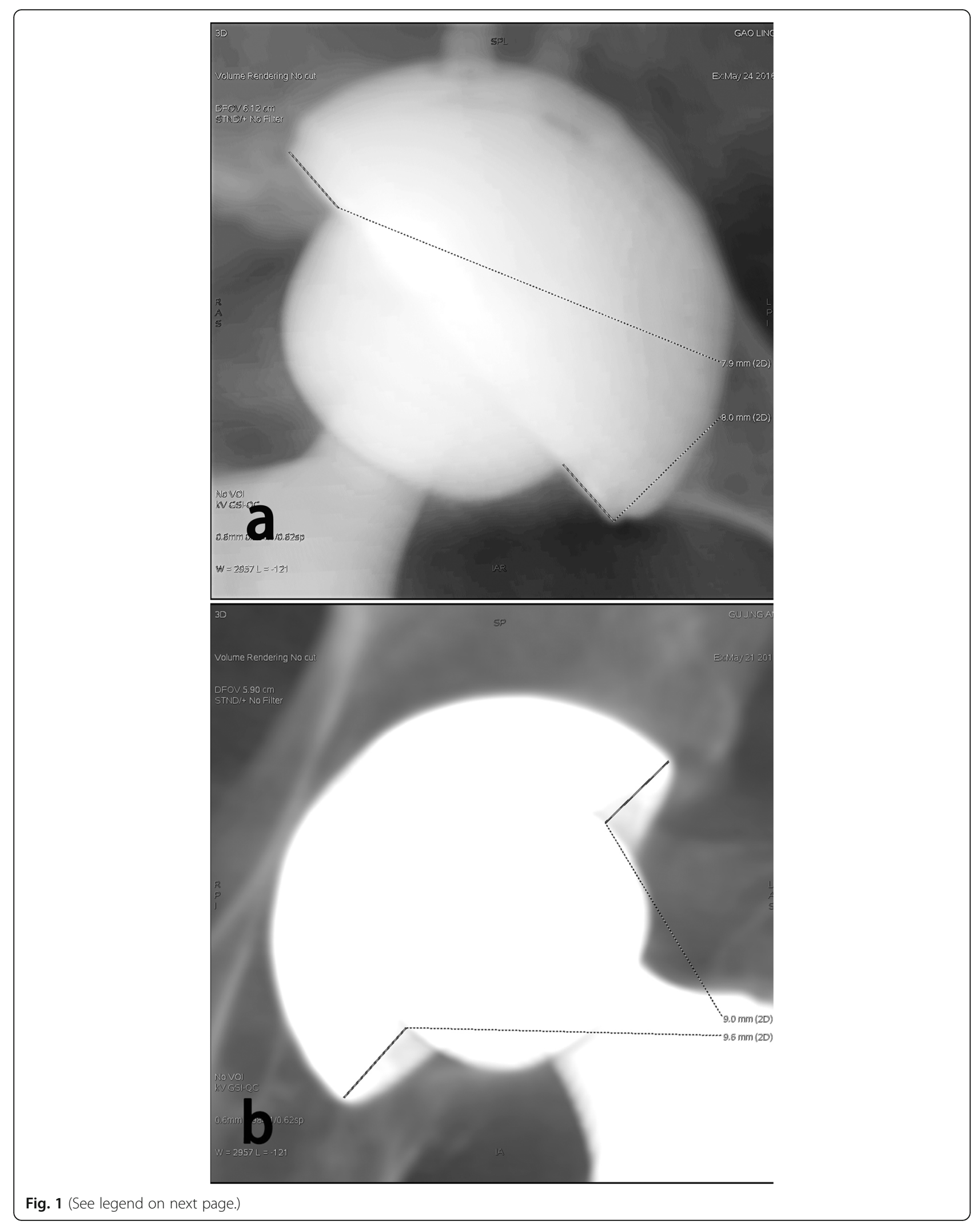


(See figure on previous page.)

Fig. 1 Measurement of femoral head penetration into the liners (measured on reconstructed CT). One line is drawn from the superior to the inferior edge of the acetabular component. The distances from the superior margin of the acetabular component to the femoral head and from the inferior margin of the acetabular component to the femoral head were measured. a A 37/F patient underwent THA with CoC bearing for right AVNF, the femoral head penetration was measured on reconstructed $C T$ at postoperative 7 years. $\mathbf{b}$ A 69/F patient underwent THA with COXPE bearing for left AVNF; the femoral head penetration was measured on reconstructed CT at postoperative 8 years

5-9-year follow-up. Participants reported significant improvements in the postoperative Harris hip score. This study also demonstrates that with an average 7 years follow-up, there is no difference in patient-reported outcome measures with SF-36 except for the sub-item of general health, suggesting that the $\mathrm{CoC}$ performs just as well as the CoXPE. The difference in general health may be related to the elder age of the CoXPE group.

There are many comparative studies that have examined the outcome comparing $\mathrm{CoC}$-bearing surface to ceramic-on-poly surfaces $[11,12,26,27]$. Atrey et al. reported comparable survivorship and function after 15 years follow-up between $\mathrm{CoC}$ and ceramic-onconventional polyethylene [11]. The hard-on-soft articulation had higher mean annual wear than hard-on-hard articulation. The author concluded that polyethylene wear and osteolysis may represent issues in the future [11]. The limitation was the cross-linked polyethylene was not adopted and the BIOLOX delta ceramic was not widely available. Beaupre et al. reported $\mathrm{CoC}$ and ceramic-on-crossfire-polyethylene had a similar healthrelated quality of life after postoperative 10 years followup. There were no failures of loss of fixation related to the bearing surface in either group. The study was limited to radiographic review with plain radiographs and no data of annual wear rate [12]. In those that had a radiographic follow-up at 10 years $(n=57$; $66 \%)$, no osteolysis was noted in either group [12]. The incidence of osteolysis in both bearings was lower than the $18 \%$ rate reported for conventional polyethylene in literature [20].
The annual wear rate in this study was similar to the wear rate in literature $[11,28,29]$.

The annual wear rate in the current study of the $\mathrm{CoC}$ group was $0.0096 \mathrm{~mm} /$ year, supporting the excellent behavior and wear resistance of the ceramic bearing [25]. The annual wear rate of CoXPE in the current study was lower than the result of ceramic-on-conventional poly in literature [11]. The result also supported the good wear resistance of highly crosslinked-polyethylene [24]. Although the mean annual wear in the CoXPE group was significantly higher than the $\mathrm{CoC}$ group $(0.047$ vs 0.011 $\mathrm{mm}$ ), the osteolysis is uncommon with a wear rate of < $0.1 \mathrm{~mm} /$ year according to the literature [30]. As a result, the current study shows that there was no difference of HHS, SF-36 scores and osteolysis between the two groups, suggesting that the $\mathrm{CoC}$ performed as well as the CoXPE.

Our study has strengths including the aim to study on the same disease and use more accurate CT data to measure the wear rate and radiological outcome. As we have known, the clinical outcome and implant survival tend to differ based on primary diagnosis [13]. Swarup et al. reported that patient diagnosis is predictive of implant survival with juvenile inflammatory arthritis patients having the lowest implant survival [13]. This study focused on THA for osteonecrosis which is one of the common etiologies for THA in our country. The study can more accurately discover the difference of outcome owing to the different bearing surface selection. CT offers a three-dimensional assessment of the liner wear in contrast to the conventional radiographic examination

Table 2 Scores for the dimensions of the SF-36 at the latest follow-up between CoXPE group and CoC group

\begin{tabular}{|c|c|c|c|c|c|c|}
\hline & \multicolumn{2}{|l|}{ COXPE } & \multicolumn{2}{|l|}{$\mathrm{CoC}$} & \multirow[t]{2}{*}{$T$ value } & \multirow[t]{2}{*}{$P$} \\
\hline & Mean & SD & Mean & SD & & \\
\hline \multicolumn{7}{|l|}{ SF-36 } \\
\hline Physical function & 77.5 & 16.1 & 83.6 & 16.2 & -1.4 & 0.167 \\
\hline Role limitation, physical problem & 11.4 & 12.7 & 10.3 & 13.9 & 0.29 & 0.773 \\
\hline Role limitation, emotional problem & 69.7 & 20.3 & 76.7 & 26.4 & -0.764 & 0.448 \\
\hline Social function & 76.7 & 23.6 & 77.2 & 15.8 & -0.095 & 0.924 \\
\hline Bodily pain & 86.4 & 17.8 & 85.0 & 18.6 & 0.276 & 0.784 \\
\hline Vitality & 72.7 & 10.4 & 75.8 & 3.8 & -1.613 & 0.113 \\
\hline Mental health & 77.1 & 11.2 & 79.8 & 5.0 & -1.277 & 0.207 \\
\hline General health & 64.7 & 21.7 & 75.5 & 14.9 & -2.198 & 0.032 \\
\hline Reported health transition & 48.8 & 9.37 & 48.5 & 8.6 & 0.137 & 0.891 \\
\hline
\end{tabular}

COXPE Ceramic-on-highly cross-linked polyethylene, CoC ceramic on ceramic, SD standard deviation 
Table 3 Comparison of postoperative complication between CoXPE and CoC for avascular necrosis patients underwent primary THA

\begin{tabular}{lllll}
\hline & CoXPE & CoC & $x^{2}$ & $P$ values \\
\hline Case number & 77 & 93 & & \\
Dislocation & 3 & 6 & 0.549 & 0.459 \\
Periprosthetic fracture & 1 & $\mathrm{~N} / \mathrm{A}$ & $\mathrm{N} / \mathrm{A}$ & $\mathrm{N} / \mathrm{A}$ \\
Noise & 2 & 8 & 2.743 & 0.098 \\
Superficial infection & 1 & $\mathrm{~N} / \mathrm{A}$ & $\mathrm{N} / \mathrm{A}$ & $\mathrm{N} / \mathrm{A}$ \\
\hline
\end{tabular}

THA total hip arthroplasty, COXPE ceramic-on-highly cross-linked polyethylene, CoC ceramic on ceramic, N/A not available

which may underestimate polyethylene wear. It was reported that CT can detect osteolysis and wear earlier than with conventional radiographic examination before loosening occurs [31].

The reported rate of squeaking and other noises for $\mathrm{CoC}$ bearing ranged from $<1$ to $21 \%$, and the etiology is multifactorial [32]. In our study, audible noise occurred in $8.6 \%$ in the $\mathrm{CoC}$ group and $2.6 \%$ in the CoXPE group. Although the difference was not statistically significant, there was a higher rate of audible noise for the CoCbearing surface than the CoXPE-bearing surface. We found no reported postoperative squeaking in our study and no difference in postoperative Harris hip scores between the noise and silent hip groups. Furthermore, no revision was required for the noise.

However, there are some limitations to our study. Firstly, this study is limited by its nature of observation study with a relatively small number of cases. However, we conducted a power analysis to determine the sample size to detect the difference of wear between the 2 groups and found that 52 cases were needed in each group. Additionally, the analysis was based on consecutive cases, with no randomization. In this study, patients who received a CoC THA were younger than those who received a CoXPE THA. This might have been caused by selection bias and may have influenced the clinical outcome results. Secondly, our study is a midterm follow-up result. Longer-term studies are needed to determine the wear rate and incidence of osteolysis for implant longevity between the two groups. Thirdly, we did not obtain a full clinical and radiographic follow-up for all of the respondents. Fourthly, we used different sized femoral heads; this may have influenced the complication of postoperative dislocation and clinical results. Finally, the ceramic insert would cost more than poly. In the current study, no costeffective analysis has been studied, which is also important for healthcare decision-making [12].

\section{Conclusion}

In summary, our results showed other than greater wear in the cross-link polyethylene group, there was no significant difference in outcome between the CoC and CoXPE THA for osteonecrosis after midterm follow-up in terms of functional outcomes, bearing surface-related complication, radiographic results, and $\mathrm{HRQL}$ outcome. Both $\mathrm{CoC}$ and CoXPE bearings can behave excellently. As for the longevity of the two bearing surfacing, long-term follow-up study will be needed.

\section{Abbreviations \\ AP: Anteroposterior; AVN: Avascular necrosis; BMl: Body mass index; CoC: Ceramic-on-ceramic; CoXPE: Ceramic-on-highly cross-linked polyethyl- ene; CT: Computed tomography; HHS: Harris hip score; HRQL: Health-related quality of life; PE: Polyethylene; SF-36: Short Form 36; THA: Total hip arthroplasty}

\section{Acknowledgements}

We acknowledge the assistance of Lijuan Zhao from Peking Union Medical College Hospital for the data collection.

\section{Authors' contributions}

BF contributed to the conception and design of the study, acquisition, and interpretation of the data, wrote the initial draft of the paper, and gave final approval of the manuscript. SC and YR contributed to the acquisition and interpretation of the data. $J \mathrm{~L}, J \mathrm{~J}$, and WQ contributed to the conception and design of the study and surgical procedure. XW contributed to the conception and design of the study, revised the initial drafts of the paper, and gave approval of the final manuscript. All authors read and approved the final manuscript.

\section{Funding}

This work was supported by a grant from the National Natural Science Foundation in China (grant number 81871740).

Availability of data and materials

All data presented in this study are available from the corresponding author upon reasonable request.

Ethics approval and consent to participate

The Regional Ethics Committee for Medical Research approved the study protocol. Informed consent was obtained from all the individual participants included in the study.

\section{Consent for publication}

Consent for publication was obtained from all the patients.

\section{Competing interests}

The authors declare that they have no competing interests.

\section{Author details}

${ }^{1}$ Department of Orthopaedic Surgery, Peking Union Medical College Hospital, Peking Union Medical College, Beijing 100730, China. ${ }^{2}$ Peking Union Medical College, Beijing 100730, China.

Received: 6 July 2019 Accepted: 10 October 2019

Published online: 27 November 2019

\section{References}

1. Kurtz SM, Lau E, Ong K, Zhao K, Kelly M, Bozic KJ. Future young patient demand for primary and revision joint replacement: national projections from 2010 to 2030. Clin Orthop Relat Res. 2009;467:2606-12.

2. Learmonth ID, Young $C$, Rorabeck $C$. The operation of the century: total hip replacement. Lancet. 2007:370:1508-19.

3. Collier JP, Surprenant VA, Jensen RE, Mayor MB, Surprenant HP. Corrosion between the components of modular femoral hip prostheses. J Bone Joint Surg Br. 1992;74:511-7.

4. Skinner JA, Haddad FS. Ceramics in total hip arthroplasty: a bearing solution? Bone Joint J. 2017;99-B:993-5. 
5. Lee $\mathrm{GC}$, Kim RH. Incidence of modern alumina ceramic and alumina matrix composite femoral head failures in nearly 6 million hip implants. J Arthroplast. 2017;32:546-51.

6. Massin P, Lopes R, Masson B, Mainard D, (SFHG) FHKS. Does BIOLOX Delta ceramic reduce the rate of component fractures in total hip replacement? Orthop Traumatol Surg Res. 2014;100(6 Suppl):S317-21.

7. Tai SM, Munir S, Walter WL, Pearce SJ, Walter WK, Zicat BA. Squeaking in large diameter ceramic-on-ceramic bearings in total hip arthroplasty. J Arthroplast. 2015;30:282-5.

8. Jarrett CA, Ranawat AS, Bruzzone M, Blum YC, Rodriguez JA, Ranawat CS The squeaking hip: a phenomenon of ceramic-on-ceramic total hip arthroplasty. J Bone Joint Surg Am. 2009;91:1344-9.

9. Glyn-Jones S, Thomas GE, Garfjeld-Roberts P, Gundle R, Taylor A, McLardySmith $P$, et al. The John Charnley Award: highly crosslinked polyethylene in total hip arthroplasty decreases long-term wear: a double-blind randomized trial. Clin Orthop Relat Res. 2015;473:432-8.

10. Bedard NA, Burnett RA, DeMik DE, Gao Y, Liu SS, Callaghan JJ. Are trends in total hip arthroplasty bearing surface continuing to change? 2007-2015 usage in a large database cohort. J Arthroplast. 2017;32(12):3777-81.

11. Atrey A, Wolfstadt II, Hussain N, Khoshbin A, Ward S, Shahid M, et al. The ideal total hip replacement bearing surface in the young patient: a prospective randomized trial comparing alumina ceramic-on-ceramic with ceramic-on-conventional polyethylene:15-year follow-up. J Arthroplast. 2018; 33(6):1752-6.

12. Beaupre LA, Al-Houkail A, Johnston DWC. A randomized trial comparing ceramic-on-ceramic bearing vs ceramic-on-crossfire-polyethylene bearing surfaces in total hip arthroplasty. J Arthroplast. 2016;31(6):1240-5.

13. Swarup I, Shields M, Mayer EN, Hendow CJ, Burket JC, Figgie MP. Outcomes after total hip arthroplasty in young patients with osteonecrosis of the hip. Hip Int. 2017;27:286-92.

14. Kim YH, Kim JS, Oh SH, Kim JM. Comparison of porous-coated titanium femoral stems with and without hydroxyapatite coating. J Bone Joint Surg Am. 2003;85:1682-8.

15. Sutherland $C J$, Wilde AH, Borden LS, Marks KE. A ten-year follow-up of one hundred consecutive Müller curved-stem total hip-replacement arthroplasties. J Bone Joint Surg Am. 1982;64:970-82.

16. Lee JH, Lee BW, Lee BJ, Kim SY. Midterm results of primary total hip arthroplasty using highly cross-linked polyethylene minimum 7-year followup study. J Arthroplast. 2011;26:1-6.

17. Goldvasser D, Hansen VJ, Noz ME, Maguire GQ Jr, Zeleznik MP, Olivecrona $\mathrm{H}$, et al. In vivo and ex vivo measurement of polyethylene wear in total hip arthroplasty: comparison of measurements using a CT algorithm, a coordinate-measuring machine, and a micrometer. Acta Orthop. 2014;85(3):271-5.

18. Engh CA, Stepniewski AS, Ginn SD, Beykirch SE, Sychterz-Terefenko CJ, et al. A randomized prospective evaluation of outcomes after total hip arthroplasty using cross-linked marathon and non-cross-linked enduron polyethylene liners. J Arthroplast. 2006;2:17-25.

19. Shi HY, Mau LW, Chang JK, Wang JW, Chiu HC. Responsiveness of the Harris hip score and the SF-36: five years after total hip arthroplasty. Qual Life Res. 2009;18(8):1053-60.

20. Hanna SA, Somerville L, McCalden RW, Naudie DD, MacDonald SJ. Highly cross-linked polyethylene decreases the rate of revision of total hip arthroplasty compared with conventional polyethylene at 13 years' followup. Bone Joint J. 2016;98-B:28-32.

21. Hannouche D, Hamadouche M, Nizard R, Bizot P, Meunier A, Sedel L. Ceramics in total hip replacement. Clin Orthop Relat Res. 2005:62-71.

22. Higuchi Y, Seki T, Takegami Y, Komatsu D, Morita D, Ishiguro N. Same survival but higher rate of osteolysis for metal-on-metalUltamet versus ceramic-on-ceramic in patients undergoing primary total hip arthroplasty after 8 years of follow-up. Orthop Traumatol Surg Res. 2018;104(8):1155-61.

23. Kumar A, Bloch BV, Esler C. Trends in total hip arthroplasty in young patients results from a regional register. Hip Int. 2017;27:443-8.

24. Tsukamoto M, Ohnishi H, Mori T, Kawasaki M, Uchida S, Sakai A. Fifteen-year comparison of wear and osteolysis analysis for cross-linked or conventional polyethylene in cementless total hip arthroplasty for hip dysplasia-a retrospective cohort study. J Arthroplast. 2017;32:161-5.

25. Nikolaou VS, Edwards MR, Bogoch E, Schemitsch EH, Waddel JP. A prospective randomised controlled trial comparing three alternative bearing surfaces in primary total hip replacement. J Bone Joint Surg Br. 2012;94(4):459-65.
26. Amanatullah DF, Landa J, Strauss EJ, et al. Comparison of surgical outcomes and implant wear between ceramic-ceramic and ceramic-polyethylene articulations in total hip arthroplasty. J Arthroplast. 2011;26(6 Suppl):72.

27. Wyles CC, Jimenez-Almonte $\mathrm{JH}$, Murad MH, et al. There are no differences in short- to mid-term survivorship among total hip-bearing surface options: a network meta-analysis. Clin Orthop Rel Res. 2015;473(6):2031.

28. Si HB, Zeng Y, Cao F, Pei FX, Shen B. Is a ceramic-on-ceramic bearing really superior to ceramic-on-polyethylene for primary total hip arthroplasty? A systematic review and meta-analysis of randomised controlled trials. Hip Int. 2015;25:191-8.

29. Lewis PM, Al-Belooshi A, Olsen M, Schemitch EH, Waddell JP. Prospective randomized trial comparing alumina ceramic-on-ceramic with ceramic-onconventional polyethylene bearings in total hip arthroplasty. J Arthroplast. 2010;25:392-7

30. Dumbleton $\mathrm{JH}$, Manley MT, Edidin AA. A literature review of the association between wear rate and osteolysis in total hip arthroplasty. J Arthroplast. 2002;17:649-61.

31. Weidenhielm L, Olivecrona H, Maguire GQ Jr, Noz ME. Prosthetic liner wear in total hip replacement:a longitudinal 13-year study with computedtomography. Skelet Radiol. 2018;47(6):883-7.

32. Imbuldeniya AM, Pearce SJ, Walter WL, Zicat BA, Walter WK. Squeaking: current knowledge and how to avoid it. Curr Rev Musculoskelet Med. 2013; 6:342-9.

\section{Publisher's Note}

Springer Nature remains neutral with regard to jurisdictional claims in published maps and institutional affiliations.
Ready to submit your research? Choose BMC and benefit from:

- fast, convenient online submission

- thorough peer review by experienced researchers in your field

- rapid publication on acceptance

- support for research data, including large and complex data types

- gold Open Access which fosters wider collaboration and increased citations

- maximum visibility for your research: over $100 \mathrm{M}$ website views per year

At BMC, research is always in progress.

Learn more biomedcentral.com/submissions 